\title{
Investigating psychological distress level and its association with demographic characteristics in nurses
}

\author{
달 Fatemeh Hatef, ${ }^{1} \oplus$ Azam Maleki, $^{2} \oplus$ Kourosh Amini, $^{2} \odot$ Esmail Khodadadi $^{3}$
}

'Department of Medical Surgical Nursing, Nursing and Midwifery School, Zanjan University of Medical Sciences, Zanjan, Iran ${ }^{2}$ Social Determinants of Health Research Center, Zanjan University of Medical Sciences, Zanjan, Iran

${ }^{3}$ Iranian Social Security Organization, Urmia, Iran

\begin{abstract}
Objectives: Nursing is a highly stressful profession due to the long hours, workload, and extreme physical and psychological demands it places on individuals and their families. Research has shown that nurses, as compared to physicians, experience less social support and job security, and that their roles are not socially recognized. This study aimed to identify the level of distress by demographic characteristics of Iranian nurses working at various hospitals in Zanjan, Iran in 2019.

Methods: This descriptive correlational study targeted 264 nurses working at various hospitals in Zanjan, Iran in 2019. The random cluster sampling method was used for sample selection, and for data collection, a demographic and social characteristics form and the Kessler Psychological Distress Scale were used. Data were analyzed with SPSS statistical software (version 21), which was used to perform student's t-test and ANOVA.

Results: The results from calculation of the nurses' mean score indicated that their psychological distress was at a moderate level (25.15 \pm 8.77 ). Gender, marital status and type of employment significantly corresponded with the nurses' levels of psychological distress $(p<0.05)$. Furthermore, there was a significant negative relationship between age and work experience with psychological distress among the nurses $(p<0.05)$.

Conclusion: The findings derived from this study indicate that a majority of the nurses had some degree of psychological distress, which negatively affected the quality of health care they provided. Thus, appropriate steps, like in-service training for stress management, should be taken to ensure the psychological and physical health of Iranian nurses.

Keywords: Demographic characteristics; nurses; occupational profile; psychological distress.
\end{abstract}

$\mathrm{O}$ n a global scale, nurses constitute the largest group of healthcare staff. Thus, the quality of health care largely depends on how nurses provide services and as such, they play an important role in changing the healthcare system. ${ }^{[1]}$ The nursing profession involves a high level of psychological distress as a result of the high workload and the variety of physical and psychological stressors the profession entails. [2] Psychological distress is a major factor in nurses' performance, the quality of care they provide, and their satisfaction levels. ${ }^{[3,4]}$ In some studies, long working hours, high workload, poor social support and job insecurity have been emphasized as factors contributing to nurses' psychological distress. ${ }^{[5,6]}$

Distress results from an unfavorable state of emotional and psychological stimulation, such as when a person views a situation as dangerous or threatening to their comfort. All human beings are exposed to a variety of stressors and stressful events in their daily lives that can threaten their mental and physical health. Medical personnel commonly use the term distress in reference to a physical, emotional, and psychological problem. ${ }^{[7]}$

Address for correspondence: Kourosh Amini, Social Determinants of Health Research Center, Zanjan University of Medical Sciences, Zanjan - Iran Phone: +98 2433148387 E-mail: korosh@zums.ac.ir ORCID: 0000-0001-6588-1548

Submitted Date: January 18, 2020 Accepted Date: July 07, 2020 Available Online Date: October 05, 2020

${ }^{\circ}$ Copyright 2020 by Journal of Psychiatric Nursing - Available online at www.phdergi.org 


\section{What is known on this subject?}

- Numerous studies have investigated the psychological distress status of nurses, with results generally showing that the level of psychological distress in nurses is high.

What is the contribution of this paper?

- The results from this study showed that there is a relationship between some of the demographic characteristics of the nurses, such as gender, marital status, work experience and employment type, and their levels of psychological distress.

What is its contribution to the practice?

- Based on the results of this study, to decrease the level of psychological distress experienced by nurses and to improve their overall mental health, especially for female staff, it is suggested that in-service training programs on stress management be routinely implemented.

Psychological distress is a general concept of mental performance incapacity when encountering stressful stimuli. In some texts, psychological distress is considered equivalent to destruction of morale and cynicism about the future, anxiety, inferiority, withdrawal from society and isolation, and physical disorder. Psychological distress may be accompanied by symptoms and indications like sadness, immobility, insomnia, restlessness, irritability, anger, rapid breathing and rapid heartbeat. ${ }^{[7]}$ Research findings, including the present study's, have shown that psychological distress among nurses is at a moderate to high level, ${ }^{[8-10]}$ and that at these levels the performance and quality of nursing care could be negatively affected. Moreover, a study by Okwaraji et al in Nigeria reported that the prevalence of psychological distress among nurses is rising. ${ }^{[11]}$

Given this situation, as well as the fact that nurses are at the forefront of providing services to patients, improving their health can have a positive impact on the quality of nursing care, whereas, conversely, psychological distress can negatively affect their performance. Results reported in a number of studies indicate that various factors are associated with the psychological distress of nurses. ${ }^{[12-14]}$ For example, nurses in Iran have been shown to endure a high workload ${ }^{[15]}$ due to the shortage of nurses in the country, ${ }^{[16]}$ and moreover, with the low incomes nurses receive ${ }^{[17]}$ and the dominance of physicians in the Iran health care system, ${ }^{[18]}$ nurses experience high levels of stress and are exposed to many mental illness, including depression. There are only a limited number of studies, however, that have looked at the relationship between nurses' psychological distress and their demographic characteristics. Therefore, given the importance of the subject and the lack of research in this field in Iran, this study was conducted to assess psychological distress on the basis of the demographic characteristics of nurses in the city of Zanjan in Iran.

\section{Materials and Method}

\section{Study Design}

This research was designed as a descriptive analytical study.

\section{Research Setting}

The research setting for this study included four active hos- pitals in Zanjan, 3 of which are educational hospitals affiliated with Zanjan University of Medical Sciences (1-Ayatollah Mousavi Hospital, 2- Hazrat Valiasr Hospital, and 3- Shahid Beheshti Hospital). The other hospital is affiliated with the Social Security Organization. Zanjan, which is the capital of Zanjan Province in Iran, is located in Iranian Azerbaijan and includes a largely Azerbaijani population.

\section{Participants}

The study included the participation of 264 nurses who were working in hospitals of Zanjan in 2019. At the time of the study, a total of 884 were working within these hospitals. This study looked at studies of a similar nature to determine the sample size. Calculation of sample size was performed at $95 \%$ confidence interval and $a=0 / 05$, the results of which showed that 264 nurses should be included. Taking into account possible loss of participants, the sample size was increased to 274 . A total of 10 nurses withdrew from the study, so data analysis was performed on the 264 nurses who completed the questionnaires. The list of all nurses was obtained through the hospital managers, with whom the present author worked in coordination to attain. The study samples were selected by cluster random sampling from the proportion of nurses in different wards of each hospital. With this method, each of the eligible nurses was assigned a code, and these codes were then selected using random number allocation software. The inclusion criteria applied for participation in the study were that the nurses hold a bachelor's or master's degree and have at least one year of work experience. Data collection lasted from February 2019 to July 2019. Prior to providing the nurses with the questionnaires, the researcher $(\mathrm{FH})$ visited the nurses' workplace to introduce himself and inform them about the objectives of the study and the ethical considerations the study would observe.

\section{Data Collection}

This study used two data collection tools:1- a demographic and social characteristics questionnaire 2- the Kessler Psychological Distress Scale. The demographic and social characteristics questionnaire included questions on age, sex, marital status, educational level, employment status, work unit, work shift, and work experience. The Kessler Psychological Distress Scale (K-10) was developed in2002 and includes 10 questions arranged on a five-point Likert-type scale ( $1=$ Never, $2=$ Very Low, 3=Low, 4=Often and 5=Always). The minimum score possible is 10 and the maximum is 50, with lower scores indicating lower level of psychological distress and higher scores indicating higher level of psychological distress. The validity and reliability of this tool was assessed and confirmed by Kessler himself. ${ }^{[19]}$ For use on the Iranian population, the validity and reliability study of the questionnaire was performed by Jafar Ataei et al., who determined the cut-off points for the questionnaire items to be as follows: low $<20$, Mild, ${ }^{[20-24]}$ Moderate ${ }^{[25-29]}$ and Severe $>30 .{ }^{[20]}$ 


\section{Ethical Considerations}

This research was approved by the Ethics Committee of Zanjan University of Medical Sciences in Iran (Code of Ethics: IR.ZUMS. REC.1397.367). Informed consent to participate in the study was obtained from all participants, and they were assured of the confidentiality of the information they provided.

\section{Data Analysis}

The collected data were analyzed using SPSS statistical software ver.21. Analyses included descriptive statistics (frequency, percentage, mean, standard deviation) and inferential statistics, such as t-test and ANOVA test. The normalization of data distribution was verified using the Kolmogorov-Smirnov test.

\section{Results}

A total of 264 nurses participated in the study. Results from the demographic and social characteristics questionnaire showed that the mean age of the nurses was $31.75 \pm 6.7$ years, 62 of them were male (23.5\%) and $202(76.5 \%)$ were female, and that a majority of them were married $(66.3 \%)$ and had bachelor's degree (92.8\%). Table 1 shows the details of the participants' information. The ANOVA test indicated that there was a significant difference between the age and work experience of the nurses and their psychological distress $(p<0.05)$. Specifically, nurses who were older and had more work experience had less psychological distress compared to that of other nurses. In addition, the results from the independent t-test indicated that there was a significant relationship between the gender and marital status of the nurses and their levels of

Table 1. Demographic characteristics of nurses and their relationship with psychological distress

\begin{tabular}{|c|c|c|c|c|}
\hline \multirow[t]{2}{*}{ Variables } & & \multirow[t]{2}{*}{ n (\%) } & Psychological distress & \multirow[t]{2}{*}{ Sig. } \\
\hline & & & (Mean \pm Standard deviation) & \\
\hline & Male & $62(23.5)$ & $22.48 \pm 8.30$ & \\
\hline \multirow[t]{2}{*}{ Marital status } & Single & $89(33.7)$ & $25.71 \pm 8.56$ & $t=2.05, p=0.04$ \\
\hline & Married & $175(66.3)$ & $22.62 \pm 8.24$ & \\
\hline & Master's & $18(6.8)$ & $24.78 \pm 7.21$ & \\
\hline \multirow[t]{4}{*}{ Employment status } & Official & $85(32.2)$ & $25.19 \pm 8.81$ & $F=2.79, p=0.018$ \\
\hline & Trial & $5(1.9)$ & $30.40 \pm 11.73$ & \\
\hline & Contractual & $123(46.6)$ & $25.49 \pm 9.80$ & \\
\hline & Part time & $51(19.3)$ & $25.72 \pm 8.96$ & \\
\hline \multirow{2}{*}{ Ward type } & Emergency & $59(22.3)$ & $26.25 \pm 8.60$ & \\
\hline & General & $128(48.5)$ & $24.34 \pm 9.22$ & \\
\hline \multirow[t]{4}{*}{ Age (years) } & $21-30$ & $145(54.9)$ & $24.28 \pm 8.27$ & $F=2.58, p=0.001$ \\
\hline & $31-40$ & $87(33)$ & $27.23 \pm 9.44$ & \\
\hline & $41-50$ & $30(11.4)$ & $22.41 \pm 6.52$ & \\
\hline & $51-60$ & $2(0.8)$ & $20.22 \pm 1.28$ & \\
\hline \multirow[t]{3}{*}{ Work history (years) } & $1-10$ & $175(66.3)$ & $24.93 \pm 8.65$ & $F=3.19, p=0.04$ \\
\hline & $11-20$ & 79 (29.9) & $25.91 \pm 9.24$ & \\
\hline & $21-30$ & $10(3.8)$ & $20.70 \pm 2.58$ & \\
\hline
\end{tabular}

Table 2. Nurses' ratings regarding the level of psychological distress

\begin{tabular}{lccc}
\hline Variable & Level & $\mathbf{n}(\%)$ & Mean \pm Standard deviation \\
\hline Psychological distress & Low $<20$ & - & - \\
& Mild $(20-24)$ & $116(43.9)$ & $20.17 \pm 8.74$ \\
& Moderate $(25-29)$ & $124(47)$ & $25.12 \pm 8.86$ \\
& Severe $>30$ & $24(9.1)$ & $30.75 \pm 8.70$ \\
& Total & $100(100)$ & $25.15 \pm 8.77$ \\
\hline
\end{tabular}


psychological distress $(p<0.05)$. That is, psychological distress was found to be greater in single, female nurses than that of others. Regarding the variables related to nursing jobs, the results from the ANOVA showed that the type of nursing employment had a significant relationship with the nurses' level of psychological distress $(p<0.05)$. In particular, the post hoc test results showed that the nurses who had trial employment status experienced more psychological distress than that of others.

The mean score of the nurses' psychological distress was $25.15 \pm 8.77$, which is considered as moderate. More specifically, $43.9 \%$ of the nurses had mild psychological distress, $47 \%$ had moderate psychological distress, and $9.1 \%$ had severe psychological distress (Table 2).

\section{Discussion}

This study was performed to investigate the relationship between the demographic characteristics and psychological distress of nurses working in Zanjan hospitals. The results of this study showed that the nurses had a moderate level psychological stress, as determined by their scores on the questionnaire. The results of other studies performed in this field likewise show that the psychological distress of nurses is mostly moderate, and that in most cases, the nurses suffer from psychological distress due to the stressful nature of nursing work. ${ }^{[8,11,21]}$ The results of the study by Akbari et al. ${ }^{[8]}(2009)$ reported that the mean score of stress due to environmental stressors in nurses was higher than that due to personal and family stressors, and that most of the nurses who participated had moderate levels of stress. In the study by Hebrani et al. ${ }^{[22]}$ it was observed that the highest intensity of stressors among nurses working in a hospital environment was related to the stress generated by management. Koh et al. ${ }^{[23]}$ (2014), in their study, reported that nurses attributed the psychological distress and gastrointestinal disorders they experienced to rotational work shifts. The study by Okwaraji et al. ${ }^{[11]}$ showed that burnout and psychological distress were common among nurses; and that $44.1 \%$ of nurses had a moderate level of psychological distress, which is consistent with the results of the present study. To continue, the results of a study conducted in 2002 by Smith Major et al. ${ }^{[24]}$ confirmed that long-term presence at the workplace was significantly associated with work-family interference, and that work-family interference, in turn was associated with depression and stress-related problems. Farhadi et al. ${ }^{[25]}$ also reported that factors such as the death of a patient and problems with colleagues can cause stressful situations; they found that $58.35 \%$ of nurses were moderately stressed, which is consistent with the results of the present study.

The results from this study revealed that the level of psychological distress of the nurses was related to their gender and marital status, that is, distress was more common among single, female nurses, which seems reasonable given the emotional nature and sensitivity of women and the greater emotional support married people have. Other research studies in this area also report that the level of psychological distress is higher among women. ${ }^{[26-28]}$ For example, the results reported in the study by Sabahi et al. ${ }^{[29]}$ indicated that the levels of occupational stress, psychosomatic complaints and anxiety among female staff were higher than those of men. Moreover, the study by Cockerham et al. ${ }^{[30]}$ showed that psychological distress was higher in women than in men, results consistent with those found in the present study. However, in contrast with these findings, a study conducted by Bahrami ${ }^{[31]}$ in Iran reported that there was no relationship between occupational stress and the gender of the staff. This difference between the results of the present study and those of Bahrami could be attributed to the participants involved the two studies. The results from a Study which conducted by Danesh ${ }^{[32]}$ (2005) in Iran showed that the level of achievement and overall level of physical and mental health in married students were higher than those of single students, and that there were lower physical symptoms, symptoms of anxiety, sleep disorder, depression and social dysfunction in married students than those of single students. In a study by Lincoln et al. it was also found that married people reported more happiness and satisfaction in life and their psychological distress was lower, ${ }^{[33]}$ both of which are consistent with the results of our study.

The results also indicated that the nurses' psychological distress was correlated with their age and experience, being lower among older nurses and nurses with longer work experience. According to research, older people with more work experience are more experienced, and therefore, they can better manage their stress in the face of life's problems. The amount of stressors and level of psychological stress have been shown to be higher in younger employees and in those with less work experience. ${ }^{[34-36]}$ The results of a study conducted by Halvani et al. in Iran reported that people who were younger and had a few years of work experience had more job-related stress. ${ }^{\left[{ }^{[3]}\right]}$ In addition, the study by Byles et al. ${ }^{[35]}$ found that psychological distress was lower in older people, except in the case of people who were over the age of 80 and suffered from a disability. Finally, Birditt et al., ${ }^{[36]}$ in their study, showed that interpersonal stress was lower in older people than in younger people, which is consistent with the present study's results.

The results from this study showed that the nurses' psychological distress was related to their type of employment, being higher among nurses who had trial employment status, as compared to the employment status of others. This could be because trial employment means the employee is always being closely monitored and there is no job security, which in turn generates anxiety from fear of being rejected and stress from uncertainty. The results of the study by Bahrami ${ }^{[31]}$ in Iran, however, indicated that the type of employment status did not correlate with the level of job stress, which is inconsistent with the results from the present study. Nonetheless, in general, the results of most research indicate that uncertain employment status imposes a great deal of stress on staff, ${ }^{[37,38]}$ and that unemployment has a direct and inverse relationship with mental health. ${ }^{[39]}$ The results of a study by Sidorchuk et 
al. ${ }^{[38]}$ in Sweden showed that unemployment and temporary employment could cause a great deal of psychological distress. Likewise, Mantler et al. ${ }^{[37]}$ also found that the uncertainty of the employment situation puts a lot of stress on employees, which is consistent with the results of the present study.

\section{Conclusion}

Overall, the findings from this study indicate that a large percentage of the nurses have some degree of psychological distress, which can have a negative impact on their work and psychological performance. The results confirm that some of the social and personal characteristics of nurses are related to their levels of psychological distress, which should be taken into greater consideration by health authorities and administrators. Therefore, it is suggested that in-service training programs on stress management be routinely implemented in order to improve the mental health of nurses and minimize their psychological distress. The findings of this study can be a starting point for future research and a basis for research on promoting the professional health of nurses and identifying the factors affecting them. There were some limitations in this study that are important to note. First, this study relied on information obtained through the self-reporting of the participating nurses and their completion of the questionnaire. Secondly, the research question addressed on the stressors related to the demographic characteristics of the nurses, meaning the stressors related to the workplace were not taken into consideration. Future studies on this topic should therefore examine these factors. Lastly, this study was performed only with nurses in Zanjan, which restricts generalization of the results. It is recommended that similar studies be conducted on a wider scale in other places in Iran to enable generalization of the results and to clarify the issue of psychosocial distress in terms of amount. Finally, in addition to Iran, similar studies should be conducted elsewhere in the world, especially in developing countries, to find the right solutions to address these problems.

\section{Acknowledgments}

This article is part of a research project approved by the Social Factors Research Center affiliated to Zanjan University of Medical Sciences. The Ethics Committee of Zanjan University of Medical Sciences granted permission for the conduct of this study with approval No: IR.ZUMS.REC.1397.367. We extend our appreciation and thanks to the Vice-Chancellor for Research of Zanjan University of Medical Sciences, the Research Center for Social Factors Affecting the Health of Zanjan, and all the nurses who participated in this research.

Conflict of interest: There are no relevant conflicts of interest to disclose.

Peer-review: Externally peer-reviewed.

Authorship contributions: Concept - F.H.; Design - K.A.; Super- vision - K.A.; Fundings - A.M.; Materials - F.H.; Data collection \&/or processing - E.K.; Analysis and/or interpretation - E.K.; Literature search - A.M.; Writing - F.H.; Critical review - E.K.

\section{References}

1. Truglio-Londrigan M, Lewenson SB. Public health nursing: Practicing population-based care: Jones and Bartlett Learning; 2017.

2. Vafaee Najar A, Habashizade A, Karimi H, Ebrahimzade S. The effect of improvement of nursing managers' professional competencies based on performance on their productivity: An interventional study. Daneshvar 2011;18:63-72.

3. Sarafis P, Rousaki E, Tsounis A, Malliarou M, Lahana L, Bamidis $P$, et al. The impact of occupational stress on nurses' caring behaviors and their health related quality of life. BMC Nurs 2016;15:56.

4. Boamah SA, Read EA, Spence Laschinger HK. Factors influencing new graduate nurse burnout development, job satisfaction and patient care quality: a time-lagged study. J Adv Nurs 2017;73:1182-95.

5. Ibrahim S, El Sayed R, Attala M, Elmezin N. Relationship between head nurses' leadership styles and staff nurses' job performance. IOSR J Nurs Sci 2016;5:66-74.

6. Kunie K, Kawakami N, Shimazu A, Yonekura Y, Miyamoto Y. The relationship between work engagement and psychological distress of hospital nurses and the perceived communication behaviors of their nurse managers: A cross-sectional survey. Int J Nurs Stud 2017;71:115-24.

7. Ridner SH. Psychological distress: concept analysis. J Adv Nurs 2004;45:536-45.

8. Akbari F, Amirabadizadeh H, Poor Reza A, Vagheie Y, Dastjerdi R. Survey of socio-psychological stresses among nurses working in Birjand teaching hospitals. J Birjand Univ Med Sci 2005;12:66-72.

9. Bastos RA, Quintana AM, Carnevale F. Psychological Distress Experienced by Nurses who Work with Patients in Death Process: A Clinical-Qualitative Study. Trends Psychol 2018;26:795805.

10. Jayawardene W, Youssefagha A, LaJoie S, Torabi M. Psychological distress among nurses caring for victims of war in Sri Lanka. Disaster Med Public Health Prep 2013;7:278-86.

11. Okwaraji FE, Aguwa EN. Burnout and psychological distress among nurses in a Nigerian tertiary health institution. Afr Health Sci 2014;14:237-45.

12. Ghawadra SF, Abdullah KL, Choo WY, Phang CK. Psychological distress and its association with job satisfaction among nurses in a teaching hospital. J Clin Nurs 2019;28::4087-97.

13. Bazazan A, Dianat I, Rastgoo L, Zandi H. Relationships between dimensions of fatigue and psychological distress among public hospital nurses. Health Promot Perspect 2018;8:195-9.

14. Mohammadi S, Roshanzadeh $M$. The relationship between psychological empowerment and psychological strain among clinical nurses in educational hospitals. J Nurs Manag 2014;3:51-60.

15. Arab Z, Piri L, Arsalani N, Tabatabai Ghomshe F, Biglarian A. 
The correlation of workload and work ability with job stress in nursing staff. Journal of Health Promotion Management 2015;4:21-30.

16. Zarea K, Negarandeh R, Dehghan-Nayeri N, Rezaei-Adaryani $M$. Nursing staff shortages and job satisfaction in Iran: issues and challenges. Nurs Health Sci 2009;11:326-31.

17. Mazdaki A, Rezapour A, Azari S, Harati Khaliabad T, Behzadifar M, Razi Moghadam M, et al. A comparison of the earnings of specialist physicians and nurses before and after implementing the Iran's New Tariffs Book. Med J Islam Repub Iran 2018;32:37.

18. Vaismoradi M, Salsali M, Esmaeilpour M, Cheraghi MA. Perspectives and experiences of Iranian nurses regarding nurse-physician communication: a content analysis study. Jpn J Nurs Sci 2011;8:184-93.

19. Kessler RC, Barker PR, Colpe LJ, Epstein JF, Gfroerer JC, Hiripi E, et al. Screening for serious mental illness in the general population. Arch Gen Psychiatry 2003;60:184-9.

20. Ataei J, Shamshirgaran S, Iranparvar M, Safaeian A, Malek A. Reliability and validity of the Persian version of the Kessler psychological distress scale among patients with type 2 diabetes. J Appl Environ Biol Sci 2015;4:217-23.

21. Zou G, Shen X, Tian X, Liu C, Li G, Kong L, et al. Correlates of psychological distress, burnout, and resilience among Chinese female nurses. Ind Health 2016:54.

22. Hebrani P, Behdani F, Mobtaker M. Evaluation of stress factors in nurses of different hospital wards. Journal of Fundamentals of Mental Health 2008;10:231-7.

23. Koh SJ, Kim M, Oh DY, Kim BG, Lee KL, Kim JW. Psychosocial stress in nurses with shift work schedule is associated with functional gastrointestinal disorders. J Neurogastroenterol Motil 2014;20:516-22.

24. Major VS, Klein KJ, Ehrhart MG. Work time, work interference with family, and psychological distress. J Appl Psychol 2002;87:427-36.

25. Farhadi M, Hemmati Maslakpak M, KHalkhali H. Job stressors in critical care nurses. J Urmia Nurs Midwifery Fac 2014;11:87583.

26. Cossette $\mathrm{S}$, Frasure-Smith N, Lespérance F. Nursing approaches to reducing psychological distress in men and women recovering from myocardial infarction. Int J Nurs Stud 2002;39:479-94.

27. Wichman $\mathrm{CL}$, Ehlers SL, Wichman SE, Weaver AL, Coddington
C. Comparison of multiple psychological distress measures between men and women preparing for in vitro fertilization. Fertil Steril 2011;95:717-21.

28. Elwér S, Harryson L, Bolin M, Hammarström A. Patterns of gender equality at workplaces and psychological distress. PLoS One 2013;8:e53246.

29. Sabahi P, Oreyzi HR. A comparative study of resources and consequences of job stress among men and women employees in Isfahan private hospitals. Contemp Psychol 2010;3:7484.

30. Cockerham WC, Hinote BP, Abbott P. Psychological distress, gender, and health lifestyles in Belarus, Kazakhstan, Russia, and Ukraine. Soc Sci Med 2006;63:2381-94.

31. Bahrami A, Akbari H, Mousavi SGA, Hannani M, Ramezani $Y$. Job stress among the nursing staff of Kashan hospitals. KAUMS Journal 2011;15:366-73.

32. Danesh E. A Comparison Of Happiness, Physical and mental health in male and female students'married and single of university. J Appl Psychol 2011;4:56-71.

33. Lincoln KD, Chae DH. Stress, marital satisfaction, and psychological distress among African Americans. J Fam Issues 2010;31:1081-105.

34. Khoshakhlagh A, Halvani GH, Laal F, Mihanpoor $H$, Moradi $M$. The Study and Determination of Occupational Stress and Effect of Shift Work on Pelletizing Plant Workers. Occup Med 2015;7:41-51.

35. Byles JE, Gallienne L, Blyth FM, Banks E. Relationship of age and gender to the prevalence and correlates of psychological distress in later life. Int Psychogeriatr 2012;24:1009-18.

36. Birditt KS, Fingerman KL, Almeida DM. Age differences in exposure and reactions to interpersonal tensions: a daily diary study. Psychol Aging 2005;20:330-40.

37. Mantler J, Matejicek A, Matheson K, Anisman H. Coping with employment uncertainty: a comparison of employed and unemployed workers. J Occup Health Psychol 2005;10:200-9.

38. Sidorchuk A, Engström K, Johnson CM, Kayser Leeoza N, Möller J. Employment status and psychological distress in a population-based cross-sectional study in Sweden: the impact of migration. BMJ Open 2017;7:e014698.

39. Strandh M, Hammarström A, Nilsson K, Nordenmark M, Russel $\mathrm{H}$. Unemployment, gender and mental health: the role of the gender regime. Sociol Health IIIn 2013;35:649-65. 